\title{
Analysis of fracture surface of titanium-porcelain bonding by electron spectroscopy for chemical analysis
}

\author{
Yoshiteru KANNARI ${ }^{1}$, Kazuhiko ENDO ${ }^{2}$, Yusuke IDA ${ }^{2}$, Morio $\mathrm{OCHI}^{1}$ and Hiroki OHNO² \\ ${ }^{1}$ Division of Fixed Prosthodontics and Oral Implantology, School of Dentistry, Health Sciences University of Hokkaido, 1757 Kanazawa, Ishikari- \\ Tobetsu, Hokkaido 061-0293, Japan \\ ${ }^{2}$ Division of Biomaterials and Bioengineering, School of Dentistry, Health Sciences University of Hokkaido, 1757 Kanazawa, Ishikari-Tobetsu, \\ Hokkaido 061-0293, Japan \\ Corresponding author, Hiroki OHNO; E-mail: ohno@hoku-iryo-u.ac.jp
}

\begin{abstract}
Three commercially available porcelains bonded to titanium were evaluated to determine the weakest zone of the titanium-porcelain bonding structures. Tensile bond tests were performed for these specimens (NO, DU, and VI) and for Ni-Cr alloy-porcelain bonding samples that served as controls. The maximum bond strengths between porcelain and titanium and the Ni-Cr alloy subjected to different metal surface treatments were compared. Sand blasting effectively increased bond strengths in titanium-porcelain bonding materials. No statistically significant differences in the maximum bond strengths were found between the NO sample and a control; however, sample NO exhibited greater maximum bond strength than DU and VI samples. The bond strengths increased with increasing area fractions of porcelain failure on fracture surfaces. The weakest zones were investigated based on the oxygen chemical states determined by electron spectroscopy for chemical analysis, which include bridging oxygen ( $\mathrm{Si}$-O-Si), nonbridging oxygen $\left(\mathrm{Si}^{-} \mathrm{O}^{-}\right.$ $\left.\mathrm{M}^{+}\right)$, and titanium oxide $\left(\mathrm{O}^{2-}\right)$ states. We concluded that the titanium oxide layer is the weakest zone of titanium-porcelain bonding structures.
\end{abstract}

Keywords: Titanium surface treatment, Porcelain bonding, Fracture appearance, Glass structure

\section{INTRODUCTION}

Pure titanium is a valuable biomaterial because of its excellent biocompatibility, high corrosion resistance, good mechanical properties, and low allergenicity 1,2 . Dental porcelain is a restorative material with excellent biocompatibility, high compressive strength, and good esthetic appearance. However, titanium presents several drawbacks in casting such as its high melting temperature $\left(1,668^{\circ} \mathrm{C}\right)$, high affinity to oxygen, and potential bonding to casting investment materials. The recent development of casting investments and titanium casting instruments ${ }^{3-6)}$ have resulted in higher accuracy and reduced defects, thus making it possible to achieve the quality levels needed to satisfy specific clinical demands. However, two fundamental problems affect titanium-porcelain bonding. First, titanium reacts strongly with oxygen, resulting in the formation of a thick oxide layer at temperatures above $800^{\circ} \mathrm{C}$. Second, it undergoes an $\alpha-\beta$ phase transition upon heating at $882^{\circ} \mathrm{C}$, causing volume changes ${ }^{7}$. These phenomena reduce the titanium-porcelain bond strength. Moreover, the difference between the thermal coefficients of titanium $\left(8.7 \times 10^{-60} \mathrm{C}^{-1}\right)$ and conventional porcelain $(12-$ $15 \times 10^{-6 \circ} \mathrm{C}^{-1}$ ) hinders bonding between these materials. Low-fusing porcelains for titanium, which can be fired below $800^{\circ} \mathrm{C}$, have been developed ${ }^{8-10}$. However, one study has reported unfavorable clinical results, such as fracture and cracking of the porcelain on the titanium substrate $^{11)}$. Therefore, further research is needed to achieve reliable titanium-porcelain bonding, which is considered inferior to conventional metal bonding systems.
Tensile bond tests were performed to identify the most effective titanium surface treatment for titanium-porcelain bonding products obtained using three commercially available porcelains. Tensile bond strength is discussed based on fracture appearance. Electron spectroscopy for chemical analysis (ESCA) was conducted to analyze the weak zones in the titaniumporcelain bonding structure. Three-point bending deformation of the titanium-porcelain bonding specimen was also performed to obtain a flat specimen for ESCA, in which the titanium surface of the flat specimens was treated with the same surface treatment, providing maximum bond strength during the tensile bond tests. In the present study, we hypothesized that fracture occurred at the weakest zone in the titanium-porcelain bonding structure, regardless of tensile and bending failure.

The weakest zone in each titanium-porcelain bonding product was evaluated through quantitative and oxygen chemical state analyses of fracture surfaces by ESCA. To study the glass structure effects on bonding, the $\mathrm{O} 1 \mathrm{~s}$ spectra were decomposed into different oxygen chemical states including bridging ( $\mathrm{Si}-\mathrm{O}-\mathrm{Si}$ ) and nonbridging oxygen states $\left(\mathrm{Si}^{-} \mathrm{O}^{-} \mathrm{M}^{+}\right.$) as well as the oxide state (TiO-Ti).

\section{MATERIALS AND METHODS}

\section{Materials}

The characteristics of the experimental titaniumporcelain bonding products and control samples (CONT) are detailed in Table 1 . Two types of commercially available pure titanium classified as type 3 in the JIS 
Table 1 Characteristics of experimental titanium-porcelain bonding products and conventional Ni-Cr alloy-porcelain bonding control samples.

\begin{tabular}{|c|c|c|c|c|}
\hline & & Product name & Manufacturer & Abbrev. \\
\hline \multirow[b]{2}{*}{ Experimental } & Titanium (JIS type 3) & $\begin{array}{l}\text { Lot KS-70 } \\
\text { JS-3 }\end{array}$ & Kobe Steel SELEC & - \\
\hline & Porcelain & $\begin{array}{c}\text { Super Porcelain TITAN } \\
\text { Duceratin } \\
\text { Titanium Porcelain }\end{array}$ & $\begin{array}{l}\text { Noritake } \\
\text { Ducera } \\
\text { VITA }\end{array}$ & $\begin{array}{l}\text { NO } \\
\text { DU } \\
\text { VI }\end{array}$ \\
\hline Control & $\begin{array}{c}\mathrm{Ni}-\mathrm{Cr} \\
\text { Porcelain }\end{array}$ & $\begin{array}{c}\text { UNIMETAL } \\
\text { UNIBOND VINTAGE }\end{array}$ & Shofu & CONT \\
\hline
\end{tabular}

standard were evaluated. A rod-type KS-70 specimen (Kobe Steel, Kobe, Japan) was utilized for tensile bond tests, and a JS-3 casting alloy (SELEC, Osaka, Japan) was used to prepare flat specimens for ESCA. Three commercially available porcelains were used for titanium bonding: (1) Super Porcelain TITAN (NO, Noritake, Nagoya, Japan) was composed of bonding, opaque, and body porcelains, (2) Duceratin porcelain (DU, Ducera Dental GmbH, Germany) contained haft bond ${ }^{\circledR}$ and gold bond ${ }^{\circledR}$ compounds as well as opaque and body porcelains, (3) Titanium porcelain (VI, VITA Zahnfabrik Bad Säckingen, Germany) consisted of opaque and body porcelains. Conventional porcelains bonded to a $\mathrm{Ni}-\mathrm{Cr}$ alloy (UNIMETAL, Shofu, Kyoto, Japan) were used as CONT.

\section{Titanium surface treatments}

The titanium surface was ground using 600 and 1,500 grit silicon carbide paper under wet conditions, washed ultrasonically with acetone, and rinsed with distilled water for 5 min before buff polishing (PO) with an abrasive slurry of aluminum paste and distilled water. Sand blasting (SB) was performed using aluminum particles after buff PO. Next, the SB-treated surface was subjected to high temperature oxidation under vacuum $(0.1 \mathrm{~Pa})$ at a heating rate of $50^{\circ} \mathrm{C} / \mathrm{min}$ using an electric furnace (CENTURIO, Degussa Ney Dental, Yucaipa, $\mathrm{CA})$. This oxidation was performed under five heating conditions: $500-600^{\circ} \mathrm{C}(\mathrm{H} 600), 500-700^{\circ} \mathrm{C}(\mathrm{H} 700), 500-$ $800^{\circ} \mathrm{C}(\mathrm{H} 800), 500-850^{\circ} \mathrm{C}(\mathrm{H} 850)$, and $500-900^{\circ} \mathrm{C}(\mathrm{H} 900)$. Surfaces were kept at the maximum temperature for 3 min. CONT samples were also subjected to PO and SB surface treatments.

\section{Methods for bonding porcelain to titanium and $\mathrm{Ni}$ - $\mathrm{Cr}$ alloy surfaces \\ For the NO system, bonding (thickness: $0.3 \mathrm{~mm}$ ), opaque (thickness: $0.2 \mathrm{~mm}$ ), and body porcelain layers were successively applied to the treated titanium surface by a conventional brushing technique and fired after each application. For the DU system, haft bond ${ }^{\circledR}$ (thickness: 0.1 $\mathrm{mm}$ ), gold bond ${ }^{\circledR}$ (thickness: $0.1 \mathrm{~mm}$ ), opaque (thickness: $0.3 \mathrm{~mm}$ ), and body porcelain layers were successively applied to the treated titanium surface and fired after each application. For the VI system, opaque (thickness:}

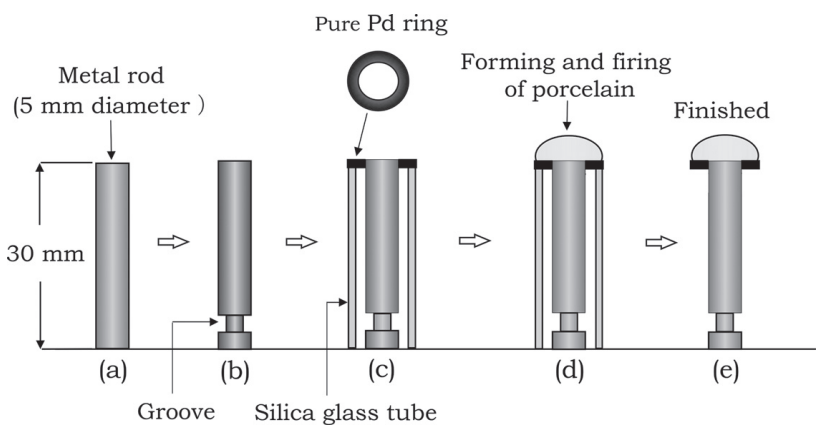

Fig. 1 Procedure for the fabrication of tensile bond test specimens.

(a) metal rod, (b) formation of a groove to facilitate insertion into the tensile test jig, (c) positioning of silica glass tube and palladium ring, (d) porcelain firing, and (e) finished tensile test specimen.

$0.3 \mathrm{~mm}$ ) and body porcelains were successively applied to the treated titanium surface and fired after each application. For the CONT opaque (thickness: $0.3 \mathrm{~mm}$ ) and body porcelains were successively applied to the treated Ni-Cr alloy and fired after each application.

\section{Tensile bond tests}

Specimens for the tensile bond tests were prepared, as shown in Fig. 1. Pure titanium rod specimens with a diameter of $5 \mathrm{~mm}$ and length of $30 \mathrm{~mm}$ were machined to form a groove for the tensile test. For the CONT, Ni-Cr alloy rods with similar shapes were obtained by casting. After surface treatment, metal specimens were inserted vertically into $29.3-\mathrm{mm}$-long silica glass tubes with an inner diameter of $8 \mathrm{~mm}$ and wall thickness of $1 \mathrm{~mm}$. A thick ring of palladium plate $(0.7 \mathrm{~mm})$ with inner and outer diameters of 5 and $9 \mathrm{~mm}$, respectively, was set at the top of each silica glass tube, maintaining flatness between the metal rod end and the palladium plate. The porcelains were applied to the end of the surface-treated metal specimens and fired using an electric furnace.

A steel ring (A) and U-shaped piece (B) (Fig. 2a) were inserted in each specimen groove, and the specimens were placed in the testing jig (Fig. 2b). The 

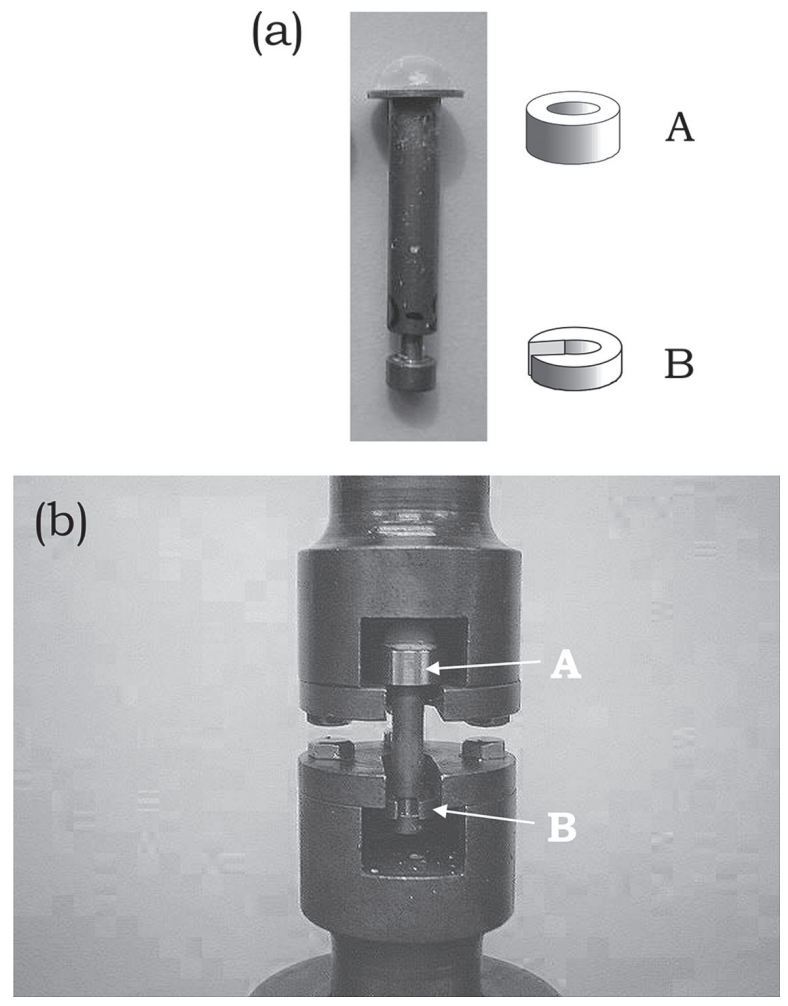

Fig. 2 (a) Tensile bond test specimens and (b) positioning of a specimen in the testing machine.

(A) Steel ring and (B) U-shaped steel piece.

tensile bond strength was measured at a cross-head speed of $0.5 \mathrm{~mm} / \mathrm{min}$ using a universal testing machine (AUTOGRAPH IS-5000, Shimadzu, Kyoto, Japan). The mean bond strengths were statistically analyzed by oneway analysis of variance and Fisher's PLSD tests at the 0.05 level of significance ( $n=10$ for each group).

Fracture appearances after the tensile bond tests were examined using an AZ100 universal zoom microscope (Nikon Inc., Tokyo, Japan). The area fraction of porcelain failure on the fracture surface was calculated using an imaging scanner (Image J, NIH, Maryland, USA). The relationship between the area fraction of porcelain failure on the fracture surface and the bond strength was determined to identify the weakest zones in the titanium-porcelain bonding structures.

\section{ESCA of fracture surfaces}

Flat titanium specimens for ESCA were cast into a $1.5 \mathrm{~mm} \times 5 \mathrm{~mm} \times 20 \mathrm{~mm}$ alumina-magnesia investment ingot (SELEVEST CB, SELEC) using an arc-melting centrifugal casting machine (VALCAN-T, Shofu) under an argon atmosphere. Cast specimen surfaces were polished, as described above, and subjected to the surface treatment producing the maximum bond strengths during tensile bond tests. For NO and VI samples, the surfaces were treated under $\mathrm{H} 700$ heating conditions. For the DU sample, the surface was sand blasted without heating treatment. Porcelains with a thickness of approximately $1.5 \mathrm{~mm}$ were fired on the titanium specimen surface using an electric furnace, (Cerafusion VRF, Morita, Tokyo, Japan), as described above. In three-point bending deformation of the flat specimen, the porcelain was peeled from the titanium surface by applying a load at the center of the metal side of the specimen with a $15 \mathrm{~mm}$ span at a cross-head speed of $0.5 \mathrm{~mm} / \mathrm{min}$ using a universal testing machine, until the porcelain layer broke away.

ESCA was performed using a specialized instrument (ESCA-850, Shimadzu, Kyoto, Japan) with Mg Ka radiation $(1,253.6 \mathrm{eV})$ at a pressure of $2 \times 10^{-6} \mathrm{~Pa}$, maintained using a turbomolecular pump. The binding energies of the measured photoelectron peaks were calibrated by the $\mathrm{C} 1 \mathrm{~s}$ peak of hydrocarbon contamination at a binding energy of $285.0 \pm 0.2 \mathrm{eV}$. Elemental analysis calculations using the ESCA spectrometer considered only the photoelectron cross section. The $\mathrm{O}$ 1s spectra were decomposed to different chemical states using the data analysis function of the ESCA spectrometer by approximating the spectra using Gaussian functions.

\section{Standard specimens for ESCA of O 1s spectra}

$\mathrm{SiO}_{2}$ (Wako Chemical, Osaka, Japan) and $\mathrm{Na}_{2} \mathrm{O}$ (SigmaAldrich, Ayrshire, UK) were used as starting materials for the standard glass specimen of the $\mathrm{O} 1 \mathrm{~s}$ spectra of bridging ( $\mathrm{Si}-\mathrm{O}-\mathrm{Si}$ ) and nonbridging oxygen $\left(\mathrm{Si}-\mathrm{O}^{-} \mathrm{Na}^{+}\right.$). A $\mathrm{SiO}_{2}-\mathrm{Na}_{2} \mathrm{O}$ mixture $\left(\mathrm{SiO}_{2} / \mathrm{Na}_{2} \mathrm{O}=7: 3\right)$ was heated in a platinum crucible at $1,550^{\circ} \mathrm{C}$ for $30 \mathrm{~min}$ in air using an electric furnace (SSFT-1520, Yamada Denki, Tokyo, Japan). $\mathrm{TiO}_{2}$ (Wako Chemical) was used as a standard specimen for the $\mathrm{O} 1 \mathrm{~s}$ spectrum of the oxide state $\left(\mathrm{O}^{2-}\right)$.

\section{RESULTS}

\section{Determination of bond strength by tensile tests}

Figure 3 shows the bond strengths of titanium-porcelain products NO, DU, VI, and CONT. PO-treated titaniumporcelain specimens exhibited significantly lower bond strengths than products that underwent other surface treatment, showing that SB affected the bond strengths most significantly and that high temperature oxidation treatments did not have a noticeable influence. Bond strengths reached a maximum when titanium was treated by $\mathrm{H} 700$ for NO, SB for DU, and H700 for VI, and when the Ni-Cr alloy was subjected to SB. These maxima did not show a statistically significant difference between NO and CONT $(p<0.05)$ and between DU and VI $(p<0.05)$. Conversely, NO exhibited significantly higher maximum strength than DU and VI $(p<0.05)$.

\section{Fracture formation by tensile bond test}

Figure 4 shows the formation of fractures on the metal side of all specimens after the tensile bond tests. Figure 5 shows enlarged typical fractures on the alloy side of the SB-treated CONT specimen concomitant with a cohesive failure of the porcelain (Fig. 5a) and on the metal side of the H850-treated VI specimen accompanied by a mixed failure of the porcelain (Fig. 5b, white, 79\%) and titanium oxide (black, 21\%). All failures were cohesive 




Fig. 3 Tensile bond strengths of titanium-porcelain products (i.e., NO, DU, VI, and CONT) for different titanium surface treatments.

PO: buff polishing, SB: sand blasting, H600: heating from 500 to $600^{\circ} \mathrm{C}, \mathrm{H} 700$ : heating from 500 to $700^{\circ} \mathrm{C}, \mathrm{H} 800$ : heating from 500 to $800^{\circ} \mathrm{C}, \mathrm{H} 850$ : heating from 500 to $850^{\circ} \mathrm{C}$, and $\mathrm{H} 900$ : heating from 500 to $900^{\circ} \mathrm{C}$.
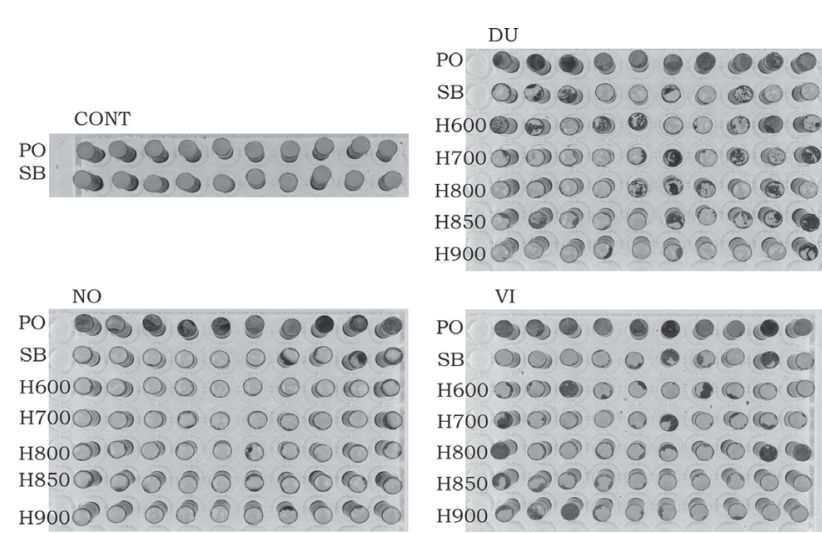

Fig. 4 Images of fracture surfaces on the metal side of NO, DU, VI, and CONT specimens after tensile bond tests.

in CONT (Fig. 4).

The relationship between the tensile bond strengths and the fraction of porcelain failure for NO, DU, VI, and CONT was investigated. The plot in Fig. 6 represents the average bond strength obtained from each surface treatment $(n=10)$. The bond strength $(y)$ increased with increasing fraction of porcelain failure $(\mathrm{x})$, yielding the linear relationship $\mathrm{y}=98.4 \mathrm{x}+39.8 \quad\left(\mathrm{R}^{2}=0.685\right)$. These results also showed that the tensile bond strength decreased with increasing fraction of titanium oxide failure on the fracture surface.

Quantitative and oxygen chemical state analyses by ESCA Quantitative ESCA of fractured porcelain-side surfaces was performed for the three titanium-porcelain bonding products (Fig. 7). The Si concentration was highest in NO (51 at\%), with equally low levels in DU (14 at\%) and VI (14 at\%). Although Ti (5 at\%) was only present in
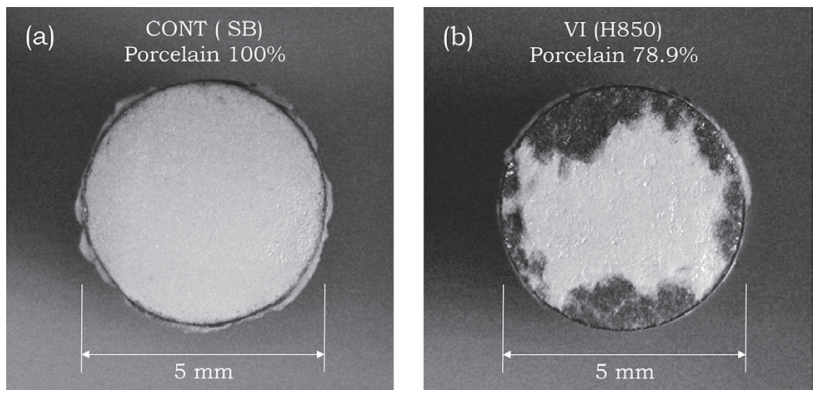

Fig. 5 Enlarged images of fracture surfaces.

(a) Alloy side of CONT (SB) showing cohesive failure in the porcelain. (b) Metal side of VI (H850) showing a typical mixed failure of porcelain (white, $79 \%$ ) and titanium oxide (black, 21\%).

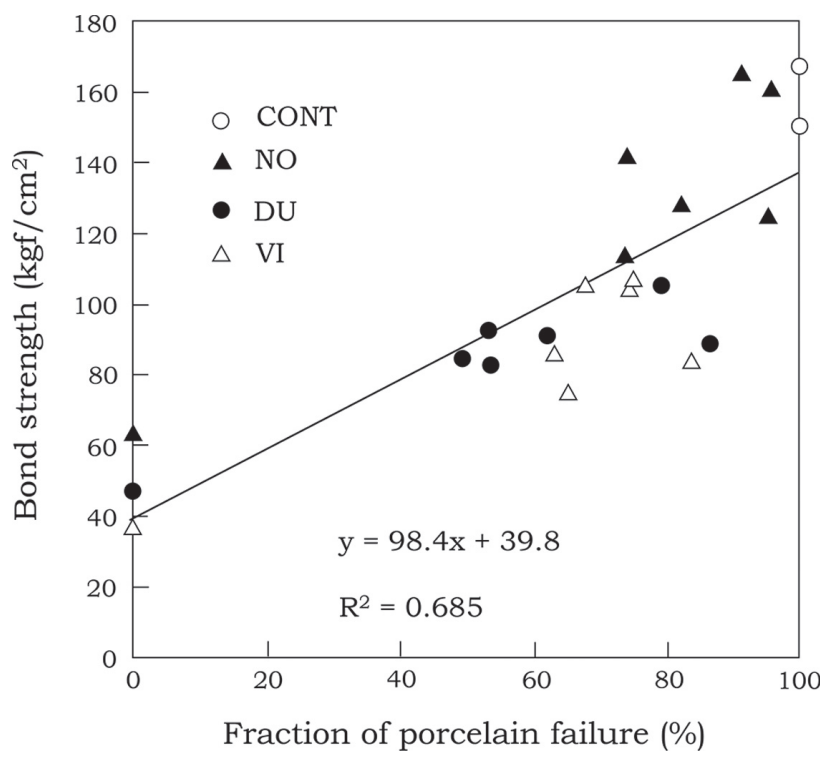

Fig. 6 Relationship between the tensile bond strength and fraction (\%) of porcelain failure for NO, DU, VI, and CONT specimens.

the opaque porcelain for VI, its concentration varied, highest in VI (46 at\%) and less abundant in DU (37 at\%) and NO (7 at\%). A higher Si content on the porcelain fracture side correlates with the fracture occurring in the porcelain, and conversely a higher Ti content on the porcelain fracture side correlates with the fracture occurring in the $\mathrm{TiO}_{2}$ layer.

Figure 8 illustrates the $\mathrm{O}$ 1s spectra obtained for the $7 \mathrm{SiO}_{2}-3 \mathrm{Na}_{2} \mathrm{O}$ standard glass specimen (a) and for the porcelain fracture side of flat NO (b), DU (c), and VI specimens (d). The measured O 1s spectra (black) were decomposed into two or three components. The $\mathrm{O} 1 \mathrm{~s}$ spectrum of the standard specimen (a) was decomposed into two components (blue I and red lines II). The O 1s spectra obtained from the three products (b, c, and d) consisted of three components (blue I, red II, and green 




Fig. 7 Quantitative ESCA of the porcelain side of NO, DU, and VI fracture surfaces.

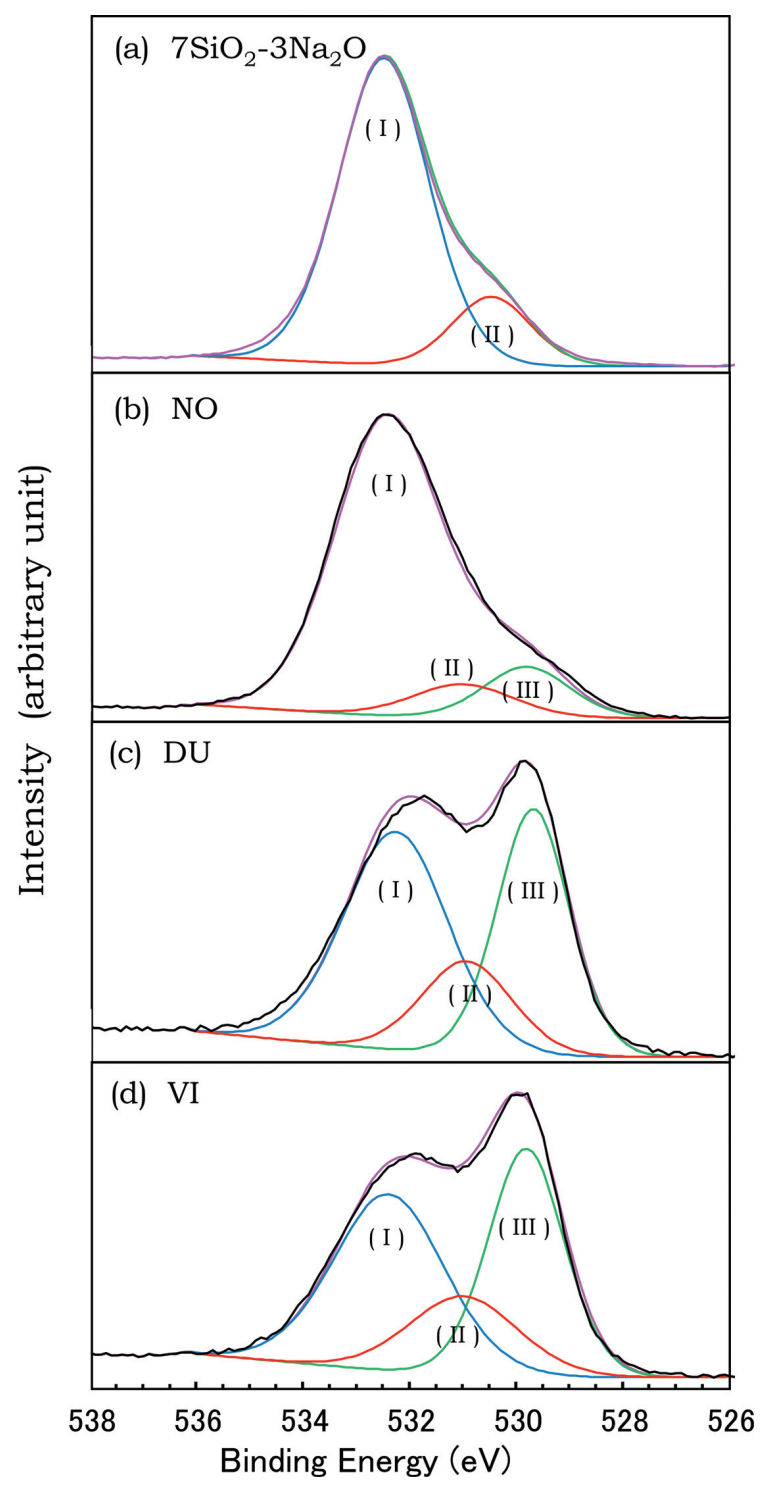

Fig. 8 ESCA O 1s spectra of (a) the $7 \mathrm{SiO}_{2}-3 \mathrm{Na}_{2} \mathrm{O}$ standard glass specimen, (b) NO, (c) DU, and (d) VI.

Each measured spectrum (black) was decomposed into components I (blue line), II (red line), and III (green line) using Gaussian functions. lines III). The violet line represents the combination of all components in each spectrum.

\section{DISCUSSION}

Effects of titanium surface treatment on bond strength The purpose of this study is to clarify which commercial products produce high bond strength under different surface treatments of titanium. Additionally, this study investigates the causes of varying bond strength among the products by investigating the weak sections of the bond structures. The bonding mechanism (i.e., mechanical retention and chemical bonding) depends on numerous factors related to the titanium surface behavior. Fused porcelain has previously displayed maximum bond strengths on titanium specimens heated at temperatures ranging from 500 to $800^{\circ} \mathrm{C}^{12)}$. In this study, the NO specimen achieved maximum bond strengths in the H700 range, consistent with the previous findings.

Watanabe et al. ${ }^{13)}$ established that fractures partly occurred at the interface between the titanium and porcelain after bending deformation. Chiang et al. ${ }^{12)}$ reported that titanium oxide fractures formed in buffpolished specimens. In addition, titanium oxide and porcelain body fractures appeared in sandblasted specimens during three-point bending tests. The appearance of fractures in CONT showed cohesive failure in the porcelain for PO- and SB-treated Ni$\mathrm{Cr}$ alloy (Fig. 4). Moreover, there were no statistically significant differences between the PO- and SB-treated specimens, suggesting that chemical factors contributed the most to bond strength in CONT.

All titanium-porcelain bonding products primarily exhibited mixed failure of porcelain and titanium oxide (Figs. 4 and 5b). The bond strength of titanium-fused porcelain has been found to increase with increasing surface roughness of the titanium substrate ${ }^{14)}$. Here, bonds in SB-treated specimens were more than twice as strong as in PO-treated specimens (Fig. 3), showing that SB effectively increased bond strength in titaniumporcelain bonding. Although the titanium oxide thickness was unknown in this study, the thickness of the titanium oxide layer should increase with higher heating temperatures and depend on bond strength. However, temperature effects were negligible compared with surface roughness of titanium under the present experimental conditions.

Higher tensile bond strengths were associated with larger area fractions of porcelain failure on the fracture surface (Fig. 6). Because the area fractions of the porcelain and titanium oxide failures displayed inverse relationships, the tensile bond strength decreased when the area fraction of titanium oxide failure increased on the fracture surface.

Oxygen chemical state analysis by ESCA

In oxides of monovalent elements, such as $\mathrm{K}_{2} \mathrm{O}$ and $\mathrm{Na}_{2} \mathrm{O}$, the bridging oxygen state produces the nonbridging $\mathrm{Si}$ $\mathrm{O}^{-} \mathrm{M}^{+}$chemical state via Si-O-Si bonding breakage. 
Brückner et $a l .{ }^{15,16)}$ have reported that $O$ 1s spectra of sodium silicate glass exhibited a pronounced shoulder on the low binding energy side of the Si-O-Si peak and that the intensity of this shoulder increased with increasing sodium content. They attributed this shoulder to nonbridging oxygen atoms linked to one silicon atom and one sodium ion and evaluated a chemical shift of $2.0 \mathrm{eV}$ for the chemical change between bridging and nonbridging oxygen states. For the standard glass specimen $7 \mathrm{SiO}_{2}-3 \mathrm{Na}_{2} \mathrm{O}$ (Fig. 8), the main peak at 532.5 $\mathrm{eV}$ and unknown state (II) were attributed to the bridging and nonbridging oxygen states, respectively.

Quantitative ESCA showed that the titaniumporcelain bonding products consisted of $\mathrm{Si}, \mathrm{Al}, \mathrm{F}, \mathrm{Na}, \mathrm{Ba}$, $\mathrm{K}$, and Sn (Fig. 7). These elements act as network formers and modifiers in silica glass. Kaneko et al. ${ }^{17)}$ measured the $\mathrm{O} 1 \mathrm{~s}$ binding energy of various orthosilicates, such as $2 M \cdot \mathrm{SiO}_{2}(M=\mathrm{Ca}, \mathrm{Ni}, \mathrm{Mn}, \mathrm{Mg}, \mathrm{Li}, \mathrm{Zn}, \mathrm{Be}$, or $\mathrm{Sn})$, in which oxygen atoms are in the nonbridging state. These binding energies were $0.8-2.0 \mathrm{eV}$ lower than those for the bridging oxygen peak. In the reaction of $\mathrm{SiO}_{2}$ and $\mathrm{In}_{2} \mathrm{O}_{3}$, Ohno et $a l .{ }^{18)}$ have also established that the binding energy of the nonbridging oxygen was shifted $2.2 \mathrm{eV}$ lower than that of the bridging oxygen.

For NO, DU, and VI, the binding energies of 532.2-532.4 $\mathrm{eV}$ for component I were attributed to the bridging oxygen state by analogy with the binding energy obtained for the standard glass specimen. The energy of chemical change between the bridging state (I) and unknown state (II) amounted to $1.4 \mathrm{eV}$ for $\mathrm{NO}$ and VI and $1.3 \mathrm{eV}$ for DU, suggesting that component II corresponds to the nonbridging oxygen state $\mathrm{Si}-\mathrm{O}^{-} \mathrm{M}^{+}$. The $\mathrm{O}$ 1s peak position of the standard $\mathrm{TiO}_{2}$ specimen was $530.0 \mathrm{eV}$, in agreement with previous findings ${ }^{19}$, indicating that component III (Fig. 8) is attributable to the oxygen state of $\mathrm{TiO}_{2}$.

Table 2 details the binding energies $(\mathrm{eV})$ and peak areas (\%) of the oxygen chemical states observed in the decomposed $\mathrm{O}$ 1s spectra obtained for the $7 \mathrm{SiO}_{2}-3 \mathrm{Na}_{2} \mathrm{O}$ and $\mathrm{TiO}_{2}$ standard specimens and the porcelain fracture side of NO, DU, and VI. Area fractions showed that the nonbridging oxygen contribution was higher in DU and VI than in NO. The oxygen chemical states mainly consisted of bridging oxygen on the fracture surface of NO. The peak intensities of component I decrease in the order $\mathrm{NO}>\mathrm{DU} \geq \mathrm{VI}$, while the peak intensities of $\mathrm{TiO}_{2}$ decreased in the reverse order $(\mathrm{VI} \geq \mathrm{DU}>\mathrm{NO})$.

Data shown in Fig. 6 only consider the relationship between tensile bond strengths and the fraction of porcelain failure. However, the strength of the porcelain itself affects bond strength. DU and VI displayed weaker bonds than NO at the same fraction of porcelain failure (Fig. 6). Table 2 shows that the contribution of component II is higher in DU and VI than in NO. In general, the bond strength of glass decreases when the contribution of the nonbridging oxygen state increases. Therefore, the lower strengths of DU and VI may be due to the higher contribution of nonbridging oxygen in these specimens than in NO.

\section{Models of the weakest zone in the titanium-porcelain bonding structure}

Figure 9 proposes a bonding model for metal and glass to evaluate the weakest zone in the titanium-porcelain bonding structure. This model consists of three different layers: the metal substrate, an oxide layer, and a glass layer. Moreover, the glass layer is divided into two sections. Section a of the porcelain substrate layer is rich in bridging oxygen atoms, while section $b$ of the reaction layer near the titanium oxide layer is rich in nonbridging oxygen atoms. Fracture in NO occurred at a position that differs from that in DU and VI, consistent with differences in the fraction of component I between the products (Table 2), suggesting that the fracture position of NO mainly occurs in glass layer section a. The fractions of component III amounted to 11, 37, and $38 \%$ for NO, DU, and VI, respectively. In DU and VI, the fraction of the fracture position in glass layer section $\mathrm{b}$ is larger than that in NO, showing that the fracture positions in DU and VI occur in glass layer sections $a$ and $b$ as well as in the titanium oxide layer. Lower tensile bond strengths were associated with higher area fractions of titanium oxide failure on the fracture surface, suggesting that this titanium oxide layer is

Table 2 Binding energies (eV) and peak areas (\%) of oxygen chemical states of decomposed O 1s spectra obtained for the $7 \mathrm{SiO}_{2}-3 \mathrm{Na}_{2} \mathrm{O}$ and $\mathrm{TiO}_{2}$ standard specimens and the porcelain fracture side of products NO, DU, and VI.

\begin{tabular}{|c|c|c|c|c|c|c|}
\hline Oxygen States & \multicolumn{2}{|c|}{ Si-O-Si } & \multicolumn{2}{|c|}{$\begin{array}{c}(\mathrm{II}) \\
\mathrm{Si}-\mathrm{O}-\mathrm{M}^{+}\end{array}$} & \multicolumn{2}{|c|}{$\begin{array}{c}\text { (III) } \\
\text { Ti-O-Ti }\end{array}$} \\
\hline $\begin{array}{c}\text { Standard } \\
\text { and products }\end{array}$ & $\begin{array}{l}\text { Peak position } \\
(\mathrm{eV})\end{array}$ & $\begin{array}{c}\text { Area } \\
(\%)\end{array}$ & $\begin{array}{l}\text { Peak position } \\
(\mathrm{eV})\end{array}$ & $\begin{array}{c}\text { Area } \\
(\%)\end{array}$ & $\begin{array}{c}\text { Peak position } \\
(\mathrm{eV})\end{array}$ & $\begin{array}{c}\text { Area } \\
(\%)\end{array}$ \\
\hline $7 \mathrm{SiO}_{2}-3 \mathrm{Na}_{2} \mathrm{O}$ & 532.5 & 84 & 530.5 & 16 & - & - \\
\hline $\mathrm{TiO}_{2}$ & - & - & - & - & 530.0 & - \\
\hline NO & 532.4 & 80 & 531.0 & 9 & 529.9 & 11 \\
\hline DU & 532.2 & 46 & 530.9 & 17 & 529.6 & 37 \\
\hline VI & 532.4 & 43 & 531.0 & 19 & 529.8 & 38 \\
\hline
\end{tabular}




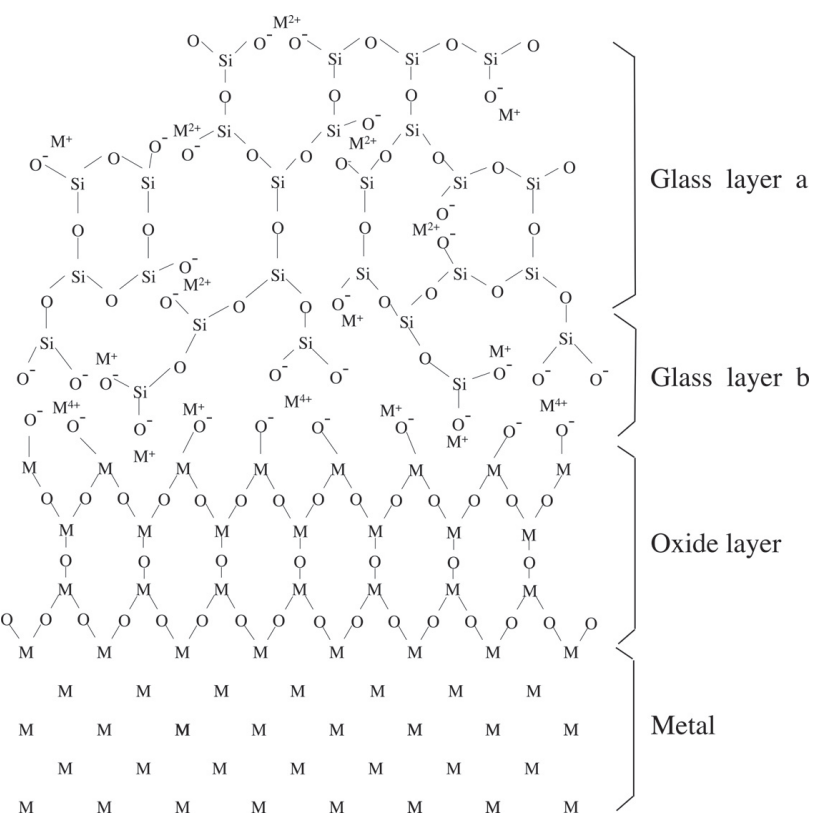

Fig. 9 Proposed bonding model for the weakest zone in the titanium-porcelain bonding structure consisting of Glass layer section a of the porcelain substrate layer, which is rich in bridging oxygen atoms; Glass layer section b of the reaction layer near the titanium oxide layer, which is rich in nonbridging oxygen atoms; and a titanium oxide layer.

The fracture position in NO mostly occurs in Glass layer section a. The fracture positions in DU and VI occur in Glass layer sections a and b as well as in the titanium oxide layer.

crucial in reducing the bond strength between titanium and fused porcelain.

\section{CONCLUSIONS}

In the present study, no statistically significant difference was found in the maximum bond strengths between NO and control specimens (Ni-Cr alloy-porcelain bonding samples); however, the maximum bond strength of NO was greater than that of DU and VI.

Oxygen chemical states in the weakest zones were examined by ESCA in the porcelain fracture side and include bridging ( $\mathrm{Si}-\mathrm{O}-\mathrm{Si})$ and nonbridging oxygen states $\left(\mathrm{Si}-\mathrm{O}^{-} \mathrm{M}^{+}\right)$and titanium oxide state $\left(\mathrm{O}^{2-}\right)$. The oxygen chemical states mainly consisted of bridging oxygen on the fracture surface of NO. The intensity of the bridging oxygen on the fracture surface of DU and VI decreased when the nonbridging oxygen and titanium oxide states increased. The fracture position of NO primarily occurs in the porcelain layer. In DU and VI, mixed fracture positions occur in the porcelain layer, reaction layer near the titanium oxide, and titanium oxide layer.

Examination of the fracture surfaces indicated that lower tensile bond strength is associated with increased fractions of titanium oxide failure. Thus, we concluded that the titanium oxide layer is the weakest zone of titanium-porcelain bonding structures. Bond strength mainly depends on the strength of titanium oxide in the bonding structure, and strong bonding requires the formation of a strong oxide layer. This may be achieved through the development of new surface treatments and new porcelain bonding systems.

\section{REFERENCES}

1) Yokoyama Y, Tajima K, Fukamizu Y, Kakigawa H, Murakami K, Uchiyama C, Kozono Y. Applicability of pure Ti and Ti6Al-4V alloy to prefabricated post: Part 2 Toxicity to culture cells. J J Dent Mater 1991; 10: 281-285.

2) Inoue M. The status of the metal allergy and the measures against it in dentistry. J Jpn Prosthodont Soc 1993; 37: 11271138.

3) Hanawa T. On titanium. J Jpn Dent Technolgist 1993; 14: $1-20$.

4) Suese K, Iwai K, Kakuta J, Ohtsuka K, Sakaida F, Kawazoe T. Prosthodontic evaluation on casting restoration of pure titanium. J Jpn Prosthodont Soc 1984; 28: 860-867.

5) Hoshino H, Kusakari H, Miyakawa O. A study on the fit of unalloyed titanium cast crowns. J Jpn Prosthodont Soc 1996; 40: 796-805.

6) Tamaki Y, Miyazaki T. Problems on titanium castings for clinical use. J Jpn Prosthodont Soc 1998; 42: 528-539.

7) Donachie MJ. Titanium: A technical guide. ASM International Metals Park, OH 44073. 1988. pp. 1-19.

8) Hegenbarth EA. Titan und Keramik Fortschrittoder Kompromiß? Quintessence Dent Technol 1992; 17: 43-54.

9) Pang IC, Gilbert JL, Chai J, Lautenschlager EP. Bonding characteristics of low-fusing porcelain bonded to pure titanium and palladium-copper alloy. J Prosthet Dent 1995; $73 ; 17-25$.

10) Suzuki Y, Okada T, Shinya A, Yokozuka S. Material property of porcelain fused to titanium. J Jpn Prosthodont Soc 1999; 43: 138-148.

11) Kaus T, Probster L, Weber H. Clinical follow-up study of ceramic veneered titanium restoration three year results. Int J Prosthodnt 1996; 9: 9-15.

12) Chiang CC, Suese K. Bond strength of porcelain fused to pure titanium and marginal distortion during the firing cycle. $\mathrm{J}$ Osaka Odontol Soc 1997; 60: 184-194.

13) Watanabe K, Okawa S, Miyakawa O, Nakano S, Honma H, Shiokawa N, Kobayashi M. Interface reactions between titanium and porcelain during firing. J J Dent Mater 1993; 12: 620-629.

14) Motomura K. Effect of titanium surface texture on bonding strength of porcelain fused to titanium. J Jpn Prosthodont Soc 1995; 39: 590-600.

15) Brückner R, Chun HU, Goretzki H. Discrimination between bridging and non-bridging oxygen in sodium silicate glasses by means of X-ray induced photoelectron spectroscopy (ESCA). Glastechn Ber 1976; 9: 211-213.

16) Brückner R, Chun HU, Goretzki H. Photoelectron spectroscopy (ESCA) on alkali silicate- and soda aluminosilicate glasses. Glastechn Ber 1978; 51: 1-7.

17) Kaneko Y, Suginohara Y. Fundamental studies on quantitative analysis of $\mathrm{O}^{0}, \mathrm{O}^{-}$, and $\mathrm{O}^{2-}$ ions in silicate by X-ray photoelectron spectroscopy. J Japan Inst Met Mater 1977; 41: 357-380.

18) Ohno H, Ichikawa T, Shiokawa N, Ino S, Iwasaki H. ESCA study on the mechanism of adherence of metal to silica glass. J Mater Sci 1981; 16: 1381-1390.

19) Chastain J. Handbook of X-ray Photoelectron Spectroscopy. St. MN: Perkin-Elmer; 1992. pp.73-74. 